\title{
REDES VIRTUALES, NUEVO ESPACIO \\ PARA EL ARTE. UNA LECTURA DESDE LA \\ TRANSGRESIÓN
}

VIRTUAL NETWORKS, NEW SPACE FOR ART.
A READING FROM THE TRANSGRESSION

María Begoña Fernández Cabaleiro

Universidad Complutense de Madrid

Resumen Los nuevos medios y espacios expositivos en red están provocando profundas transformaciones en el entramado artístico constituido a lo largo de la historia. Surge una nueva forma de afrontar la creación de obras de arte y los espacios donde mostrarlas al público: el espacio virtual se convierte en una realidad viva y activa que ensombrece a los espacios tradicionales como museos o galerías. La reproductibilidad técnica que apuntaba Walter Benjamin ha dado paso a la difusión ilimitada de la obra de arte a través de redes sociales donde la obra de arte es objeto de manipulación, transformación y transgresión, de importantes consecuencias. La gran obra de arte ha salido del santuario expositivo de museos y galerías de colecciones. La red casi infinita es el nuevo espacio de la obra transgredida. El público anónimo es el gran transgresor transformador.

Palabras clave Arte-red, transgresión, museo, espacio virtual, redes sociales, reproductibilidad técnica, apropiación.

Abstract The new media and networked exhibition spaces are causing deep transformations in the artistic fabric that has been constituted throughout history. A new way of tackling the creation of works of art and the spaces in which to show them to the public is emerging: the virtual space becomes a living and active reality that overshadows traditional spaces such as museums or galleries. The technical reproducibility pointed out by Walter Benjamin has given way to the unlimited diffusion of the work of art through social networks where the work of art is the object of manipulation, transformation and transgression, with relevant consequences. The great work of art has left the exhibition sanctuary of museums and collection galleries. The almost infinite network is the new space for the transgressed work. The anonymous public is the great transforming transgressor.

Keywords Art-network, Transgression, Museum, Virtual Space, Social Networks, Technical Reproducibility, Appropriation. 
Ante estos dos esquemas podemos plantearnos cómo se ha desarrollado el proceso para llegar a este fenómeno que actualmente nos invade. Debemos reflexionar también sobre la posibilidad de que nos encontremos ante un hecho efímero, que no dejará huella alguna, o ante una nueva forma de afrontar la creación de obras de arte y los espacios donde mostrarlas al público: el espacio virtual se convierte en una realidad viva y activa que ensombrece a los espacios tradicionales como museos o galerías. Todos los parámetros sobre los que se sustenta el armazón artístico consolidado durante siglos están sufriendo un profundo cambio.

\section{La transgresión del entramado artístico en perspectiva histórica}

A lo largo de la historia se han ido produciendo transformaciones en los planteamientos estéticos y artísticos que podrían definirse como auténticas transgresiones, especialmente a partir del siglo XIX. Una importante transgresión se produce en el periodo del Romanticismo que quiebra la normatividad clásica.

En la segunda mitad el siglo XIX podemos encontrar en el pensamiento de Nietzsche las bases filosóficas de una segunda y profunda transgresión artística. Su filosofía a martillazos y el concepto de transvaloración (Nietzsche, 2001) rompen con las formas de pensamiento tradicionales y tendrán un eco que se mantiene a lo largo del siglo xx. Paralelamente, según las teorías de Sigmund Freud (Freud, 1996), el inconsciente sustituye a la razón y en el pensamiento de Karl Marx (Marx, 1983) se cuestiona el sistema cultural burgués. Sobre estas bases se desarrollarán los caminos artísticos de la primera mitad del siglo $\mathrm{xx}$, se cuestionarán sus instituciones y las formas tradicionales de mostrar y comercializar la obra de arte.
La tercera gran transgresión se define cuando en los años 70 del siglo xx Lyotard expone la condición postmoderna y anuncia la muerte de los grandes relatos del cristianismo, ilustración, marxismo y capitalismo (Lyotard, 1987).

En este proceso, las últimas décadas marcan el desarrollo de un fenómeno que está cambiando los parámetros históricos del arte. A la Gran Obra de Arte parece que se le ha perdido completamente el respeto. El fenómeno que en su día apuntaba Walter Benjamin (Benjamin, 2008) se ha desbordado y, lo que era una reproductibilidad ilimitada, se ha convertido en una irreverente manipulación y transformación, una transgresión de los límites, que tiene importantes consecuencias.

La gran obra de arte ha salido del santuario expositivo en que parecen haber derivado museos y galerías de colecciones. Este cambio se produce a través de la constante muestra de las obras de arte históricas y de su transformación con medios digitales. Su difusión a través de espacios virtuales y de redes sociales, hace que la imagen de la obra manipulada sea conocida por cualquier receptor antes y mejor que la obra de arte original, histórica, pudiendo darse el caso, incluso, de que esta última tal vez nunca llegue a ser conocida por el receptor de la imagen transformada.

Como ejemplo y para ilustrar este planteamiento, podemos ver algunas imágenes seleccionadas entre los centenares que se han recogido y clasificado para elaborar un completo recorrido por toda la Historia del Arte Occidental. El fin es ofrecer una breve panorámica histórica del Arte Occidental, transformado por una manipulación transgresora que ha dado lugar al cambio de los parámetros de todo el entramado artístico: 


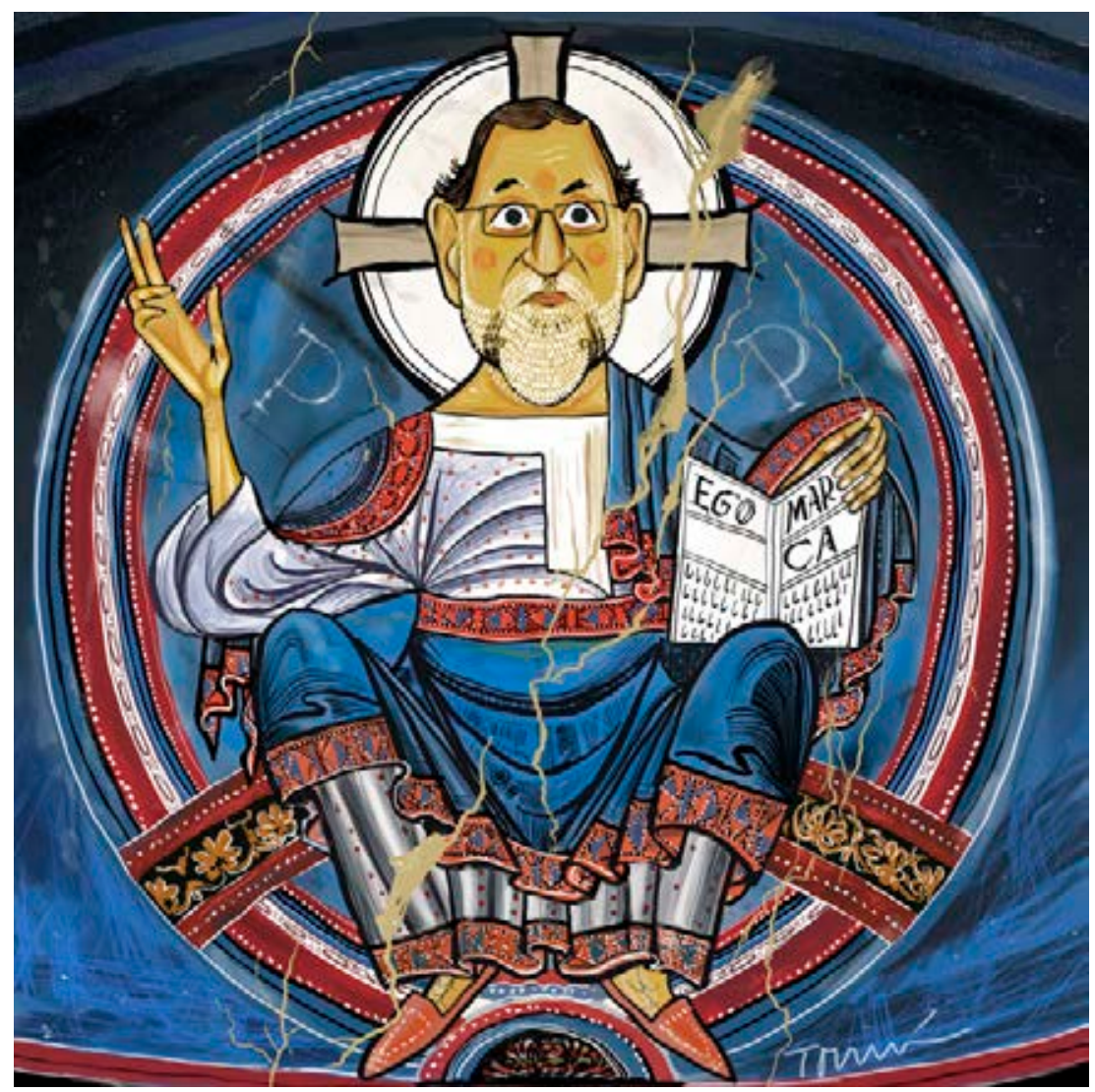

(C) Tomás Serrano. Todos los derechos reservados

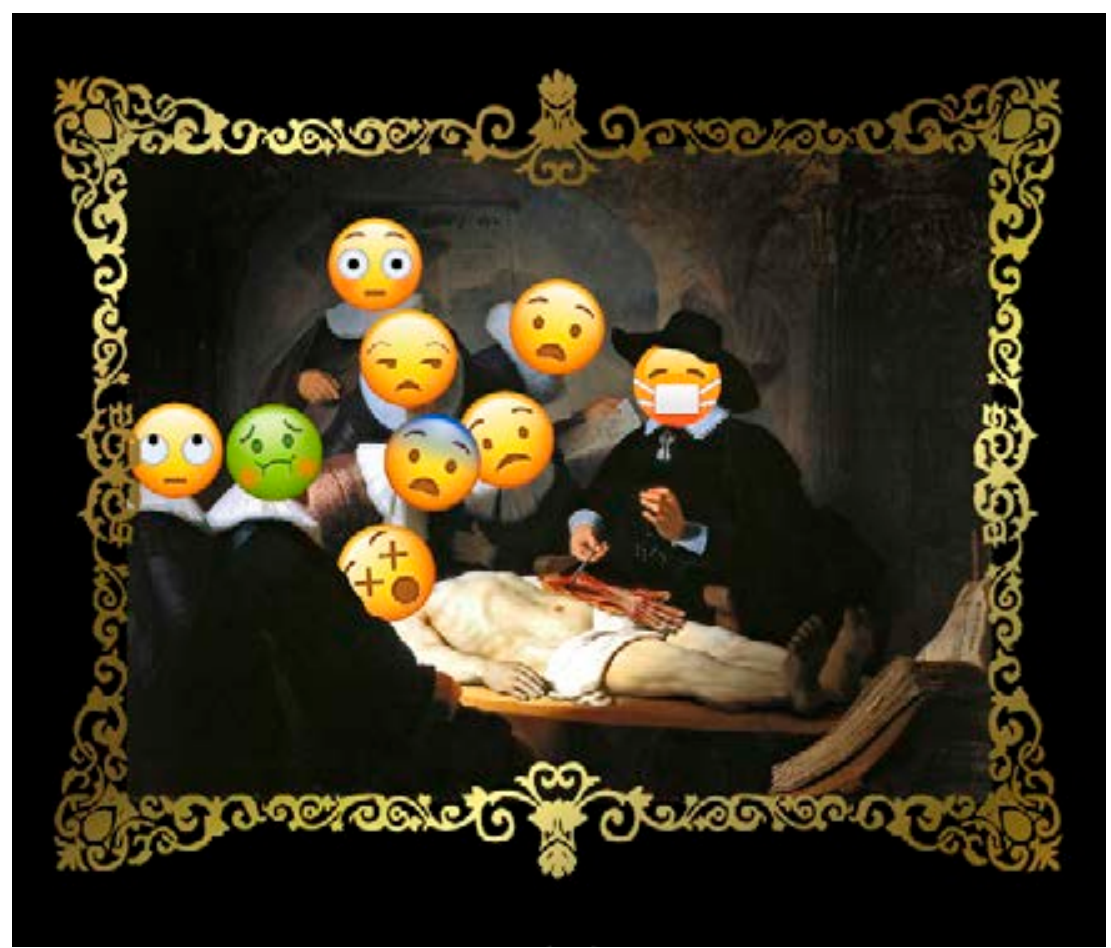

The Anatomy Lesson of Dr. Nicolaes Tulp by Rembrandt van Emoji, 2019 @ Sarai Llamas 


\section{La obra de arte en el ámbito de las redes sociales}

En esta reflexión partimos de la consideración de que la transformación/transgresión de la obra de arte se produce principalmente en el ámbito digital y con el fin de ser expuesta y difundida a través de los medios que este mismo ha generado, principalmente redes sociales. Este hecho ha tenido un proceso de desarrollo desde el inicio de los medios digitales como herramienta de trabajo intelectual.

Manuel Castells se refiere a la network society o sociedad red, término que se empieza a utilizar en los años noventa, definiéndola como aquella sociedad «cuya estructura social está compuesta de redes potenciadas por tecnologías de la información y de la comunicación basadas en la microelectrónica» (Castells, 2006). A partir de este hecho, las posibilidades de comunicación y contacto se han incrementado.

Todo ello ha conformado un orden tecno-social caracterizado por la generación de fuertes dependencias de los nuevos sistemas y dispositivos tecnológicos, así como por procesos de inflación comunicativa que tomarían cuerpo a través de formas prediseñadas de interacción social y afectiva. (Martín Prada, 2015: 31).

El sistema red define por tanto la morfología en red de las sociedades de consumo como una forma o estructura en red, que caracteriza la vida de estas sociedades y el cada vez mayor protagonismo de esta forma de conectividad con todas sus posibilidades comunicativas y de relaciones. Ante el crecimiento de este nuevo campo de relación, expresión y comunicación que es el network surgirán inevitablemente nuevos campos y nuevas formas de creación artística.

Inicialmente, el papel de la crítica cultural y de las manifestaciones artísticas comprometidas será el de ofrecer una visión crítica hacia los aspectos más negativos del sistema red en cuanto a las relaciones económicas y de poder que subyacen tras él, aunque proponga un sistema idílico de posibilidades comunicativas y afectivas. En consecuencia, se pretendería ir abriendo camino a

... formas de vida en red alternativas, menos parasitadas por los intereses del nuevo capitalismo informacional. De ahí la cercanía e incluso fusión de muchas de las propuestas del nuevo arte de Internet con prácticas activistas en red o con ciertas iniciativas vinculadas a los movimientos de software libre y de código abierto. En efecto, una parte muy importante de las manifestaciones en línea más comprometidas tratará precisamente de rescatar de su creciente colonización empresarial nuestros deseos de compartir, contribuir, estar en contacto o cooperar en red. Así, muchos artistas ensayarán la tematización crítica de esa estructura profundamente inclusiva y globalizadora (Martín Prada, 2015: 33).

Hay que tener en cuenta, además, todas las posibilidades de expresión e intento de emancipación que se han abierto con el crecimiento de las interacciones comunicativas a través de las redes. Con el crecimiento de Internet y de todas sus manifestaciones y posibilidades expresivas, surgió primero la mirada de muchos artistas sobre este fenómeno, mirada expresada a través de sus obras y haciendo uso de los medios informáticos -Net Art- para la creación de las mismas.

Pero, esos mismos medios de expresión, de comunicación a través de la red, de manejo y transformación de las imágenes con los propios medios informáticos, ha dado lugar a todo un fenómeno de creación. Esta forma de comunicación, no solo crea nuevas manifestaciones artísticas sino que actúa sobre las imágenes existentes y reconocidas de la Historia del Arte 
transformándolas en medios de expresión, crítica, broma, ironía, sacándolas de la quietud áurica del espacio museístico para, una vez transformadas, situarlas en un espacio de circulación y comunicación sin delimitar y sin límites.

Ante este fenómeno que se está produciendo constantemente es necesario hacer una reflexión y considerar ante qué tipo de hecho plástico o cultural nos encontramos. Podemos plantearnos si estas constantes nuevas manifestaciones son obras de arte sin aura, si son simplemente imágenes anodinas que no merecen consideración alguna más allá del momento crítico que representan, en una clave de humor más o menos sutil, o si son el inicio de una nueva forma de manifestación artística donde los históricos elementos constitutivos del entramado artístico están siendo modificados y donde los museos y espacios expositivos tradicionales son sustituidos por el espacio virtual.

Por una parte tenemos la gran obra de arte tal como se ha desarrollado en la Modernidad y su asimilación histórica, que ha generado todo un mundo complejo y cargado de intereses económicos. Junto a este hecho aparece esa obra de arte transformada, manipulada, transgredida, que nace, se desarrolla y se extiende casi totalmente en el ámbito network y que se crea para su difusión a través de las redes sociales o network society principalmente. Arte-red fruto de y hecho para una sociedad-red.

\section{Arte-red en un espacio red. Una interpre- tación desde distintos autores}

4.1. La pérdida del aura. Obra de arte y reproductibilidad técnica hoy. Walter Benjamin

Desde la pérdida del aura que en su día definió Walter Benjamin (Benjamin, 2008), la obra se está volviendo fugaz y plural. Su valor ya no puede ser medido de acuerdo con su funcionamiento dentro de la tradición. Walter Benjamin relacionó este fenómeno con una tendencia social general: la incapacidad para percibir la singularidad. La pérdida del aura supone una forma de percepción con un sentido para lo igual que ha crecido tanto que incluso por medio de la reproducción le gana terreno a lo irrepetible. En el momento en el que la norma de autenticidad fracasa en la producción artística, se transforma la función íntegra del arte.

Además de la atrofia del aura, Benjamin reflexiona también sobre la atrofia de la experiencia artística. Todos los nuevos acontecimientos históricos vividos desde finales del siglo XIX modificaron la forma de relación de los hombres entre sí, con la naturaleza y con el universo simbólico en el que se encuentran inmersos. Se modifica el lugar y la forma de trato con las obras de arte. El nuevo individuo solo es capaz de tener vivencias o vivencias de shock, en vez de la vieja experiencia de lectura reposada de la obra en el marco de la tradición. El arte en esta nueva etapa, ofrece lo que Benjamin llama iluminaciones profanas, vivencias de un shock revelador de sentido. Las obras del Dadaísmo y Surrealismo eran ejemplos claros en su tiempo. Benjamin reivindica las iluminaciones como shock emancipador, revelador de un sentido profano que en un mundo ya sin tradiciones es salvado así de pérdidas irremisibles.

\subsection{Desde un hombre/sociedad unidimensio- nal. Herbert Marcuse}

Marcuse al reflexionar sobre la normalización de la unidimensionalidad del hombre en la sociedad capitalista se refiere a los valores de la vanguardia en el arte cuando afirma que «la lucha contra su absorción en la unidimensionalidad predominante se muestra en los 
esfuerzos de la vanguardia por crear un distanciamiento que haría la verdad artística comunicable otra vez» (Marcuse, 1993). Intenta así una reorientación de la cultura hacia el arte como un medio de transformación del hombre, sometido a las necesidades creadas en él por el capitalismo.

En este caso, la acción artística transformadora de la sociedad procede de los propios artistas dentro del sistema de las artes establecido. Por eso tal vez él mismo ve las dificultades que supone provocar ese distanciamiento a través del arte para evitar la dominación. Marcuse considera que el arte es capaz de sacarnos de la vida diaria y colocarnos en otra posición que nos haga ver la realidad. Pero, aunque el arte está distanciado, no se ha separado de la realidad porque está mercantilizado. Por tanto, no se puede utilizar como medio de distanciamiento puesto que está bajo el control de la clase dominante. Queda entonces en duda la posibilidad de que el arte pueda ser herramienta para que la sociedad cambie desde dentro y trascienda su situación.

Cronológicamente, el Pop Art coincide con los planteamientos de Marcuse como reflejo de la sociedad estadounidense, donde el desarrollo vertiginoso de los medios de comunicación de masas generó una sociedad inundada de eslóganes y de marcas de productos de consumo, publicitados constantemente a través de carteles luminosos o medios como el cine y la televisión.

Jasper Johns, a finales de los 50, se apropió de diversos objetos reconocibles por todo el mundo. Peter Blake haría algo similar. Y Andy Warhol empezaría a representar repetidamente objetos cotidianos, logos y marcas como las latas Campbell's, las cajas de kétchup Heinz o Coca-Cola.

Este puede ser considerado un antecedente del fenómeno que tratamos de explicar si bien, en este caso, es la publicidad la que sufre una apropiación por parte del mundo del arte. Ahora, en la sociedad red, es el conjunto de la Historia del Arte la que parece estar sufriendo una apropiación por parte del mundo de la comunicación de todo tipo a través de los medios técnicos de comunicación.

4.3. Desde distintos planteamientos de transgresión. Georges Bataille, Georges Balandier

La obra de arte, en este proceso de apropiación por la red, sufre una constante transformación que puede analizarse desde el concepto de transgresión. El término "transgredir», en su acepción general significa quebrantar, violar un precepto, ley o estatuto. Durante la década de los 60 muchos intelectuales abogaban por la transgresión cultural. Cuando hablamos de transgresión nos estamos refiriendo a aquellos actos que franquean un límite a las normas establecidas. Su resultado es realizar un acto considerado anormal que es sancionado por la sociedad.

En este sentido la transgresión está relacionada con el límite. Esto nos lleva a cuestiones que se refieren a la ética, pero también a la política en tanto que debemos tener en cuenta a una cultura hegemónica que sostiene un poder que establece lo que está permitido y prohibido. De hecho se usa el término «transgresión» con una connotación positiva cuando ciertas acciones permiten romper tabúes y prejuicios de una cultura.

Por otro lado también se usa cuando al negar la ley lleva a acciones destructivas y autodestructivas. Mantener esta ambigüedad del concepto es una necesidad de sectores del poder para sostener que todo acto que vaya en contra de las regulaciones que impone es un atentado contra el conjunto de la sociedad. De ahí la necesidad de delimitar qué consideramos una transgresión.

Todo poder representa intereses económicos, políticos y sociales que reglamentan 
normas (leyes escritas), y preceptos culturales (usos y costumbres), que se transforman en una indicación para la vida cotidiana del conjunto social. De ahí que cualquier transgresión sigue el camino inevitable de ser desaprobada y ser considerada un hecho delictivo. Lo normal se asocia a lo natural y aquellos que transgreden esa norma realizan un acto antinatural. Este pensamiento sigue presente en la actualidad y su origen debemos rastrearlo en los mitos que fundan la cultura patriarcal.

Desde lo que venimos afirmando, cuando hablamos de transgresión se plantea una oposición entre aquéllos que sostienen la necesidad de obedecer la legalidad natural de un orden trascendente y ahistórico y aquéllos otros que afirman la inmanencia de las normas sociales. Para los primeros toda transgresión es un acto delictivo y, como tal, necesario de ser castigado.

Sin embargo si damos cuenta de la historicidad de las normas sociales propia de cada cultura, la transgresión adquiere la fuerza de oponerse a los condicionamientos que limitan la potencia del sujeto y del colectivo social. Por ejemplo los movimientos sociales realizan acciones que se sitúan en la transgresión de la legalidad. Pero estas acciones no utilizan la transgresión a la ley de forma instrumental sino para modificarla. En este sentido la transgresión implica afrontar un límite que permite ampliar la potencia del sujeto y del colectivo social en la búsqueda -como diría Spinoza- de la alegría de lo necesario. Por ello la transgresión cuestiona, y plantea otros fundamentos de las normas sociales en beneficio de la libertad y la justicia y, de esta manera, la transgresión abre paso a un nuevo suceder ignorando la norma. Las máscaras de su función como límite permiten destituir la norma por la vía de una nueva interiorización de la normatividad. De ahí que no se puede prescindir de la transgresión en tanto que es la condición en la que se orienta el devenir (González Vidaña, 2015).
Desde el punto de vista de Georges Bataille (1980), resulta indispensable representarnos a la sociedad y sus sujetos en función del respeto de prohibiciones fundamentales que limitan la irrupción de la violencia y constituyen un sistema de relaciones diferenciales. Pero es también imposible pensarlos lejos de su vocación de hecatombe, del gasto y el exceso que le son constitutivos.

Así pues, se puede comprender el mecanismo de la transgresión como una modalidad de acceso regulado a lo prohibido, al mundo sagrado, como un levantamiento ritual de las prohibiciones fundamentales que permite la emergencia y experiencia limitada de lo reprimido. Aún más, estas descargas reguladas forman parte de la cultura e incluso son fundamentales para su sostenimiento. En este marco, se pueden señalar como características fundamentales de la transgresión que caracterizan la noción batailleana que esta constituye un mecanismo ritual que levanta las prohibiciones fundamentales sin suprimirlas.

La transgresión cumple tanto con la función de descompresión como de mantenimiento y renovación de la sociedad, en este caso del arte. Es decir, en primer lugar, entendemos la transgresión como válvula de escape que permite liberar las pasiones colectivas que exigen descarga para que el ordenamiento social continúe funcionando. Se trata de un mecanismo que permite el momento de purga, de catarsis colectiva. $Y$, al mismo tiempo, tiene como función reproducir y actualizar los límites de la sociedad. Transgredir implica entonces, recrear el orden establecido en el sentido de purgar aquello que había sido excluido para volverlo a excluir.

Ahora bien, ¿qué sucede en las sociedades contemporáneas con los mecanismos de transgresión? Si bien las sociedades postradicionales creen haber evacuado su componente sagrado, por lo que se habla de estas como sociedades desacralizadas, se puede sostener, siguiendo a 
Bataille, que esta dimensión de lo sagrado aún conserva su lugar, más o menos residual, en la gramática social. Que en las sociedades seculares lo sagrado se encuentre privado de sus expresiones históricas tradicionales, no significa -según Bataille- que su sintaxis y la economía afectiva que la sostiene hayan desaparecido. Significa, más bien, que se han liberado de sus antiguas referencias, que son capaces de adquirir expresiones nuevas en espacios nuevos y que es posible que sean actualizadas drástica y dramáticamente en la acción y la imaginación colectivas, en la formación de nuevos poderes, y en la emergencia de individuos soberanos.

Podemos decir que la incorporación a la era de la racionalidad no ha cambiado nada en ese sentido y continúa conservando su fuerza. El dispositivo prohibición-transgresión continúa funcionando, incluso cuando este haya asumido nuevas formas. La transgresión continúa conservando su función como mecanismo de purga social. Y esto porque la sociedad no puede eliminar la confrontación entre la prohibición y su transgresión, entre el orden y el desorden.

Podemos pensar, siguiendo a Balandier que lo que ha cambiado en las sociedades actuales son, sobre todo, los modos en que se llevan a cabo los mecanismos rituales de transgresión en relación a la masificación de los medios de comunicación. (Balandier, 1994). La fiesta continúa existiendo en las sociedades de consumo modernas pero ya no es lo que era. Más bien, esta se ha convertido en espectáculo. En palabras de Balandier:

La civilización de los medios y de lo espectacular produce de forma trivial, cotidiana, sucedáneos parciales de la fiesta: sirve diversión a domicilio a través de la radio, la televisión y las máquinas de almacenar sonidos e imágenes [...] La progresión del consumo hace, por otra parte, menos marcado el contraste entre la economía cotidiana y la prodigalidad y el despilfarro festivos. (Balandier, 1994: 140).
Ahora la experiencia festiva puede vivenciarse mediante la imagen que de ella se produce. Y esto, tanto a partir de la multiplicación de esta temática en el cine y la literatura, como de la constante visualización televisada de eventos festivos o la prodigalidad de la repetición de la obra de arte desemantizada de su significado original y recargada de otros contenidos que la ponen en contacto con y la hacen comunicable a las nuevas generaciones intensamente relacionadas con el espacio virtual.

\section{Una conclusión abierta}

Este uso transgresor de la obra de arte rompe con el esquema tradicional de las artes, pero rompe también con todo el sistema económico y de mercado generado en el entramado artístico, pues la obra sin aura pierde también su valor económico.

Surgieron antes otros fenómenos artísticos como el street art, el graffiti, desarrollados también fuera del engranaje de mercado del arte pero, en mayor o menor medida, han sido absorbidos por él y sus obras han terminado en el espacio del museo y de la galería del arte.

¿Qué va a ocurrir con este nuevo fenómeno generador de manifestaciones artísticas a partir de obras museísticas transgredidas, manipuladas y transformadas al servicio del humor unas veces, de la crítica social, política y económica, otras, o como cuestionamiento del mismo engranaje artístico?

La Biblioteca Nacional Española inició ya un proceso de recogida de memes como elementos de valor literario del tiempo actual. Toda la industria cultural ha sufrido enormes transformaciones a lo largo de los últimos diez años, debidas no solo a la crisis económica, sino también a la revolución tecnológica.

La deriva de todo este fenómeno y concretamente en el ámbito de las artes plásticas, sigue en desarrollo. No está claro hacia dónde va pero sí es evidente que plásticamente, el 
espacio virtual da una vida nueva a la obra de arte, proporciona un espacio nuevo, dinámico, donde el espectador conecta con la obra e interactúa con ella transformándola, casi siempre de forma anónima y sin fines económicos de momento. El desarrollo queda abierto al análisis y el estudio.

El pensamiento de Bataille se encamina a la inclusión de lo excretado por la sociedad y los individuos. De esta forma, acompañada de la risa y el erotismo, se articula la representación más clara del trasmundo oculto tras los velos de lo habitual y la civilización. En el Catecismo de Dianus, Bataille lo dice de la siguiente forma: «Debes saber en primer lugar que cada cosa que tiene un rostro manifiesto posee también uno oculto».

\section{Bibliografía}

BAlANDiER, Georges (1994) El poder de las escenas. De la representación del poder al poder de la representación, Barcelona: Paidós Ibérica.

Bataille, Georges (1980) El erotismo, Barcelona: Tusquets editores.

Benjamin, Walter (2008) La obra de arte en la época de la reproductibilidad técnica. Madrid: Abada.

Carpintero, Enrique (2012) «La transgresión cuestiona lo natural del orden de la cultura», Editorial Revista Topía Abril/2012. Disponible en https://www.topia.com.ar/articulos/transgresióncuestiona-lo-natural-del-orden-cultura [Consulta abril 2018].

CAstells, Manuel (2006) La sociedad red: una visión global, Madrid: Alianza.

Foucault, Michel (1993) Prefacio a la transgresión, Buenos Aires: Trivial Ediciones.

FreUd, Sigmund (1996) «Lo Inconsciente» en Obras completas, Vol. XIV, Amorrotu, Buenos Aires, $9^{\mathrm{a}}$. Edición.
GonzÁLEZ, Braulio (2015) «Georges Bataille y la transgresión de la mirada», consultado en http:// www.fadu.edu.uy/estetica-diseno-ii/files/2015/06/ bataille.pdf [Consulta febrero 2018].

LYOTARD, Jean-François (1987) La condición postmoderna. Informesobre el saber, Madrid:Cátedra.

MARCUSE, Herbert (1993) El hombre unidimensional, Barcelona, Planeta DeAgostini.

Martín Prada, Juan (2015) Prácticas artística e internet en la era de las redes sociales, Madrid: Akal.

Marx, Karl (1983) El Capital, México: Siglo xxi.

Mitchell, William John Thomas (2019) La ciencia de la imagen. Iconología, cultura visual y estética de los medios, Madrid: AKAL Col. Estudios Visuales.

Nietzsche, Friedrich (2001) Crepúsculo de los ídolos o cómo se filosofa con el martillo, Madrid, Alianza.

PatiÑo, Antón (2017) Todas las pantallas encendidas, Madrid: Forcola. 